\title{
Neural like cells and acetyl-salicylic acid alter rat brain structure and function following transient middle cerebral artery occlusion
}

https://doi.org/10.1515/bmc-2018-0014

received October 7, 2018; accepted November 14, 2018.

Abstract: Introduction: Transient cerebral ischemia is a pandemic neurological disorder and the main aim of medical intervention is to reduce complications. Human umbilical cord mesenchymal cells (hUCMs) are capable of differentiating into neural-like cells (NLC) in vitro, therefore we investigated the neuroprotective potential of these cells in comparison to aspirin and in combination (NLC-Aspirin) on spatial memory and neural morphologic changes in male rats submitted to transient cerebral ischemia.

Methods: Ten days after the intervention, the improvement in learning and memory were assessed in the animals by Morris Water Maze. Thence, the animals were examined for the presence of $\mathrm{PKH}^{26}$ labeled cells in the ischemic area of the brain, the infarct volume and neural changes in the brain tissue.

Results: Significant spatial memory deficits in the ischemic animals were detected compared with the control animals. The learning and memory were significantly improved $(p \leq 0.05)$ in the aspirin and NLC groups compared with the ischemic animals. Co-treatment of aspirin and NLCs did not improve the outcome. Moreover, infarction volume and neural changes were significantly altered when aspirin or NLCs were administered.

Conclusions: Our data suggest the significant neuroprotective potential of aspirin and neural-like cells derived from hUCM cells in the treatment of brain ischemic stroke. Further studies are required to evaluate possible underlying mechanisms, and to evaluate the possible interactions between aspirin and stem cells in a joint treatment aimed at the recovery of cognitive impairments

\footnotetext{
*Corresponding author: Seyed Noureddin Nematollahi-Mahani, Neuroscience Research center, Shariati avenue, Tahmasbabad Cross, E-mail: nnematollahi@kmu.ac.ir

Ali Shamsara: Department of Anatomy, Afzalipour School of Medicine, Kerman University of Medical Sciences, Kerman, Iran Vahid Sheibani, Majid Asadi-Shekaari: Neuroscience Research Center, Institute of Neuropharmacology, Kerman University of Medical Sciences, Kerman, Iran
}

Keywords: ischemic stroke; neural like cell; Aspirin; TTC staining; learning and memory.

\section{Introduction}

Brain ischemic stroke (BIS) is a mainspring of disability and death in our industrial world. A large number of affected people suffer from BIS in their life (20). BIS is the leading cause of nearly $80 \%$ of all strokes and most often is generated in the middle cerebral artery (MCA) or its branches due to a thrombotic or embolic occlusion $(14,25,36)$. The first step in an effective therapy is to prevent the development of complications (14). At high risk for cerebrovascular disease, aspirin is commonly administered for the prevention of platelet aggregation through inhibition of cyclooxygenase (COX) enzyme for cerebrovascular impairments including BIS $(44,5)$. High dose aspirin administration has proven useful effects and also to has increased survival rate when given within 14 days of stroke onset (47). We have previously shown in an experimental study that high dose of aspirin could reduce infarct size when it was administered $30 \mathrm{~min}$ after the stroke onset (4).

In addition to anti-inflammatory drug administration for the prevention and treatment of BIS, the neuroprotective potential of different stem cells has come into account (18). Mesenchymal stem cells (MSC) derived from human umbilical cord matrix can differentiate into cells of the adipogenic, chondrogenic, osteogenic, cardiogenic and even neurogenic lineages under suitable conditions (17, 38). More recent reports have described the use of hUCM cell transplantation for the repair of damaged brain tissue and have improved neurobehavioral functions following ischemic stroke $(8,34,26,12)$. Whether the administration of differentiated stem cells in combination with the antiinflammatory drugs is a safe and effective procedure in the BIS patients is not well documented. In our previous study, we have evaluated the effects of co-administration of undifferentiated hUCMs and aspirin on the cerebral ischemia and did not find an improvement in the outcome 
compared with aspirin and hUCM cells alone (40). However, treatment of BIS patients with NLCs might reduce the risk of brain injury complications. In addition, neural factors that are naturally secreted by NLCs may alleviate destructive phenomenon caused by BIS $(16,24)$. We have in the present study assessed the effects of aspirin; a known neuroprotective NSAID, and NLC derived from hUCMs in the repair of BIS generated in a rat experimental model by transient occlusion of the middle cerebral artery (tMCAO); a method of choice in experimental BIS $(42,19)$. Additionally, we assessed possible positive effects of co-administration of aspirin and NLC in the recovery of spatial memory and structural changes of the stroked brain. Ten days after $\mathrm{TMCAO}$, we determined the recovery of learning and memory in the rats by Morris water maze (MWM), the extent of infarction area by 2, 3, 5-triphenyltetrazolium chloride (TTC) staining and histological changes by hematoxyline and eosin (H \& E) staining.

\section{Materials and Methods}

\section{Animal housing and surgical procedures}

The Ethics Committee at Kerman University of Medical Science, Kerman, Iran approved all experimental protocols (Ethics Code: EC/KNRC/89-47). Male Sprague-Dawley rats weighing $240-280 \mathrm{~g}$ were used in this study and kept under controlled conditions; $\left(24 \pm 2^{\circ} \mathrm{C}\right), 12 / 12$ light/dark and free access to regular chew and drinking water.

For TMCAO induction, the animals underwent anesthesia by i.p. injection of $400 \mathrm{mg} / \mathrm{kg}$ chloral hydrate solution. A skin incision was made at the midline of the neck, the right common carotid artery (CCA) was exposed and temporary ligated along with the clamping of the internal carotid artery (ICA) by a microsurgery clamp. The surgery was completed according to Tamura et al. (42). Briefly, a 20 mm long 3-0 monofilament nylon suture (with one end sealed by flame and coated with poly-d-lysine) was inserted through CCA to the clamped right ICA. The clamp was then removed and the right middle cerebral artery (MCA) was occluded by the introduction of a nylon suture into the entrance of the MCA. The nylon suture was pulled off after 20 min to allow reperfusion. The animals were returned back to their cages after suturing the fascia and skin. During the operation, body temperature was kept at $37^{\circ} \mathrm{C}$ using a heating lamp. The animals were examined for neurological signs after $24 \mathrm{~h}$ and those with a positive contralateral rotation and forelimb positive test were selected for further examination.
Experimental design: Rats were divided into five experimental groups $(n=6)$; the Control (Cont) group which did not receive any intervention, the Ischemic (Isch) group which underwent tMCAO, the Aspirin (ASA) group received $30 \mathrm{mg} / \mathrm{kg}$ aspirin via intraperitoneal (i.p.) route $30 \mathrm{~min}$ after the onset of ischemia, the NLC group received $1 \times 10^{6}$ neural-like cells via tail vein $24 \mathrm{~h}$ after the onset of ischemia, and the aspirin-NLC (ASA-NLC) group received $30 \mathrm{mg} / \mathrm{kg}$ aspirin and $1 \times 10^{6} \mathrm{NLC}$.

\section{Isolation and phenotype analysis of hUCMs}

All the chemicals were purchased from Sigma Company (Sigma- Aldrich, Mo, USA) unless stated otherwise. Isolation of mesenchymal cells from umbilical cord have been described previously (2). Briefly, umbilical cords were obtained from healthy mothers delivering term infants by Cesarean section after written consent had been obtained. Umbilical cords were transferred to the laboratory in Hank's balanced salt solution. The Wharton's jelly was cut into small pieces and was cultured onto the special dishes. Plates were maintained in Dulbecco's modified Eagle's medium (DMEM-F12) supplemented with 10\% FBS, penicillin (100 units $/ \mathrm{ml})$, streptomycin $(60 \mu \mathrm{g} / \mathrm{ml})$, and amphoteripcin-B $(2.5 \mu \mathrm{g} / \mathrm{ml})$ at $37 \stackrel{\circ}{\circ}$ humidified environment with $5 \% \mathrm{CO} 2$ in the air. After the cells migrated from the fragments borders and reached $80 \%$ confluence in two weeks. They were either used for further experiments or were cryopreserved as described elsewhere (32).

\section{Mesenchymal marker expression and differentiation}

Cells at passage two were harvested by trypsin/EDTA and a suspension of $1 \times 10^{5}$ cells $/ \mathrm{ml}$ in DMEM was prepared. CD34, 45, 73 and 90 expressions were analyzed according to Seyedi et al. (39). In addition, ability of hUCM cells to differentiate into osteogenic and adipogenic lineage were assessed, according to a previously reported method (37).

\section{Neuronal cells differentiation of hUCM cells}

Characterized hUCMs, were expanded in the laboratory and exposed to neural induction medium consisted of low-glucose DMEM, FBS, Penicillin and Streptomycin, $1 \mu \mathrm{m}$ Retinol acetate (RA; Sigma- Aldrich, USA), bFGF (10 $\mathrm{ng} / \mathrm{ml})$ and EGF (10 ng/ml) (15). The cells were maintained in neural induction medium for 6 days $\left(3^{+} / 3^{+}\right)$, followed 
by culturing in $\mathrm{DMEM} / \mathrm{F}_{12}$ for another 6 days $\left(3^{-3}\right)$. Induced cells were fixed by $4 \%$ paraformaldehyde $(\mathrm{PF})$ for immunocytochemistry (ICC) evaluations. Presence of Nestin, glial fibrillary acidic protein (GFAP) and neurofilament (NF) was assessed in the differentiated cells.

\section{Immunocytochemistry}

To confirm the differentiation of hUCM cells into neurallike cells, the slides were fixed by $4 \%$ paraformaldehyde in $0.1 \mathrm{M}$ phosphate buffer. The cells were treated by $10 \% \mathrm{H}_{2} \mathrm{O}_{2}$ to prevent non-specific antibody-antigen binding sites. The cells were then treated with the following primary antibodies at $4^{\circ} \mathrm{C}$, overnight: mouse anti-nestin monoclonal antibody (1:100, Chemicon), mouse anti-NF monoclonal antibody (1:100, Chemicon), and mouse anti-GFAP antibody (1:200, Chemicon), washed with 0.1 M PBS, reacted with secondary antibodies (Envision HRP labeled; Dako); at room temperature for 1 hour, washed again with $0.1 \mathrm{M}$ PBS and finally developed with diaminobenzidine (DAB). The slides were then counterstained with hematoxylin. In the control slides, all steps were processed, except the primary antibodies were omitted.

\section{RT-PCR (Reverse Transcription Polymerase Chain Reaction) analysis}

Total mRNA was extracted and reverse transcription was performed on $20 \mu \mathrm{l}$ of reactions using $1 \mu \mathrm{g}$ of RNA per reaction heated at $65^{\circ \mathrm{C}} \mathrm{cDNA}$ with $1 \mu \mathrm{g}$ of oligodT for 2 min. Samples were mixed with RNase reverse transcriptase (Invitrogen), dNTPs (Bioscience, Sweden) and RNAseout (Invitrogen). PCR reactions were made in a reaction using Taq DNA Polymerase (Fermentas, Canada) using an identical amount of cDNA per reaction with forward (F) and reverse (R) primers, respectively. GAPDH was used as the housekeeping gene. Primers used were Nestin (F- ATGCTCCTCTCTCTCTGCTCCA, R- CTAGTGTCTCATGGCTCTGGTTTTC) and ß-tubulin III (F- GAGCGGATCAGCGTCTACTA, RGTCGCAGTTTTCACACTCCT).

\section{Tracking transplanted cells in the brain}

NLC implantation was performed $24 \mathrm{~h}$ after the induction of tMCAO under sterile conditions. The cells were labeled with $\mathrm{PKH}^{26}$ fluorescent dye and slowly infused via the tail vein $\left(1 \times 10^{6}\right.$ cells in $\left.50 \mu \mathrm{l} \mathrm{PBS}\right)$. After recovery, the animals were caged and immunosuppressed by i.p. administration of $10 \mathrm{mg} / \mathrm{kg}$ cyclosporine A (Novartis Sandoz, Sweden). Immunosuppression was initiated $24 \mathrm{~h}$ prior to transplantation and continued daily till sacrifice at day 10 post-injury (12). To prepare animal brains for histologic studies, the rats were perfused transcardially using normal saline solution (150 $\mathrm{ml}$ ) and followed by fixation fluid ( $4 \%$ paraformaldehyde, $\mathrm{pH}$ 7.4). Ten $\mu \mathrm{m}$ thick frozen sections were prepared from rat brains (29) and stained with Hoechst solution to visualize cell nuclei.

\section{Spatial learning and memory}

We examined spatial learning and memory of the rats by using a spatial version of the MWM test on day 10 of the experiments (35). Training took place over five consecutive days. In each training period, the rats received four trials, where the invisible platform was placed in a constant location. Each trial was started from a different location and when they found the platform, they should stay on that for $30 \mathrm{~s}$. Rats which were unable to find the platform within $60 \mathrm{~s}$ were guided by the examiner. In order to assess spatial learning, the mean distance and velocity to find the invisible platform was measured for each animal. To assess long-term memory, the platform was removed from the maze $24 \mathrm{~h}$ after the final trial and the examinations carried out.

\section{Histopathology}

\section{Triphenyltetrazolium chloride (TTC) staining}

Fifteen days after the induction of $\mathrm{MCAO}$, the animals in the different groups were deeply anesthetized with chloral hydrate $(400 \mathrm{mg} / \mathrm{kg}$ I.P.) and sacrificed. The brains were removed carefully from the skull, immediately immersed in cold saline with 30\% sucrose for $10 \mathrm{~min}$ and sectioned by a brain matrix apparatus into $2 \mathrm{~mm}$ thick sections. The sections were incubated in $2 \%, 2,3$, 5-triphenyltetrazolium chloride (TTC, Sigma) solution for $1 \mathrm{~h}$. With the TTC method, the ischemic area appeared colourless while healthy areas appeared red due to the absorption of TTC dye. The region of infarction (colorless tissue) was measured using a digital scanner and an image tool program (UTHSCSA, Image Tool 3.00, San Antonio, TX, USA). The following formula was used to calculate the volume of cerebral infarction: (Infract volume - right hemisphere Volume) left hemisphere Volume $=$ corrected infract Volume $(21,27)$. 


\section{Hematoxyline and eosin (H\&E)}

Samples were fixed in $10 \%$ formalin solution, paraffin embedded, and sectioned into $7 \mu \mathrm{m}$ slices. Sections were stained by hematoxylin and eosin method to diagnose the normal and pyknotic cells. Four randomly selected fields per slide were counted at a magnification of $400 \times$.

\section{Data analysis}

Statistical analysis was carried out on the distance spent to find the hidden platform in the learning period, using one-way analysis of variance (ANOVA) along with repeated measures to determine the differences of the learning rates of the groups.

Five trials were averaged per day; therefore, the day was the only within-subject variable and group was the between-subject variable. We evaluated the data for homogeneity by Levene test; as the data were homogeneous, a univariate repeated-measure analysis of variance (RMANOVA) was used for intragroup comparison of performances of each group from days 1 to 4. By this analysis, the effect of the day for each group was assessed. For the significant values, we used pair sample $t$-tests. In between-group comparisons, we assessed data for homogeneity by Levene test; as the data were homogeneous, we used one-way analysis of variance (ANOVA) followed by Tukey's post hoc test for comparison of groups for the data of MWM. All collected data were analyzed by a one-way analysis of variance (ANOVA) from memory phase (probe trials), swim speed and histopathology data. The data were displayed as means \pm S.E.M. and a $p$ value of less than or equal to 0.05 was considered a significant difference. Calculations were performed using the SPSS statistical package (SPSS 16, SPSS Inc., Chicago, IL, USA) for Windows.

\section{Results}

\section{Morris water maze (MWM) performance}

\section{The distance traveled to hidden platform}

Analysis of day-to-day distance was performed for each group. Day-to-day intragroup comparisons of MWM training of the rats were relatively improved by day 4 when compared with day 1 performance in all groups. Pairwise comparisons of day 1- 4 performances of each group were as follows: control group ( $p=0.004)$; ischemic group ( $p=0.049)$; ASA group ( $p$ $=0.023)$; NLC group $(p=0.011)$; ASA- NLC group $(p=0.041)$. These data show that all rats had a prominent increase in learning over the 4-day test period ( $p \leq 0.05$, Table 1$)$.

Repeated measures ANOVA was used for the comparison of spatial learning distance traveled between groups (Fig. 1). The distance travelled by the treatment and control groups were not significantly different on day $1(p$ $\leq 0 / 05$ ), but a significant difference between ischemic and control groups ( $p=0.018$ ) was detected at day 2. Distance traveled in the ASA and NLC groups significantly decreased when compared with that in the ischemic group $(p=0.032$ and $p=0.049$, respectively) at day 3. On day 4, spatial learning was significantly improved in the ASA and NLC groups compared with the ischemic group $(p=0.002$ and $p=0.039$, respectively). A decrease in the distance - spent parameter in the learning phase was not significantly reduced when compared with the ischemic animals.

\section{Distance spent in the target quadrant}

The distance spent in the target quadrant (probe trial: the $5^{\text {th }}$ day) by the ischemic animals significantly reduced compared with the control group ( $p=0.001)$. Animals in the ASA and NLC groups significantly spent more distance in the target quadrant compared with the ischemic group ( $p=0.008$ and $p=0.031$ respectively, Fig. 2). However, although the animals in ASA-NLC group spent more distance in the target quadrant, it did not reach the level of significance compared with animals in the control group.

\section{Frequency in the entrance into the target quadrant}

Ischemia significantly ( $p=0.003$, Fig. 3) reduced the frequency of the entrance of the ischemic animals into target quadrant compared with the control animals. However, compared with the ischemic group, animals in the ASA and NLC groups moved significantly more frequently into the target zone ( $p=0.009$ and $p=0.015$, respectively). It also decreased in ASA- NLC group, though not significant compared with the ischemic group ( $p=0.55)$.

\section{Swim speed (velocity)}

Swim speed significantly differed between the control and ischemic group $(p=0.009)$ at the first day of trial. However, it did not significantly differ among the groups in the consecutive days (Fig. $4 \mathrm{~A}$ and B). 
Table 1: The distance spent to locate the hidden platform for intragroup comparisons in each groups (cm).

\begin{tabular}{lllll}
\hline & day1 & day2 & day3 & day4 \\
\hline Control & $741.14 \pm 3.62$ & $617.98 \pm 1.75$ & $569.03 \pm 7.93$ & $382.2 \pm 4.61^{*}$ \\
Ischemic & $1187.81 \pm 8.67$ & $1113.13 \pm 2.61$ & $1213.94 \pm 8.78$ & $951.66 \pm 0.87^{*}$ \\
ASA & $852.89 \pm 6.29$ & $749.58 \pm 3.34$ & $704.88 \pm 2.69$ & $562.93 \pm 2.28^{*}$ \\
NLC & $1059.01 \pm 1.98$ & $842.35 \pm 5.69$ & $745.61 \pm 3.78$ & $631.18 \pm 7.01^{*}$ \\
ASA- NLC & $955.78 \pm 8.85$ & $945.17 \pm 3.09$ & $865.65 \pm 9.36$ & $749.3 \pm 2.10^{*}$ \\
\hline
\end{tabular}

Spatial learning performance in different groups: “*” designates a significant difference at day 4 performance in either group ( $p<0.05$ ). "Repeated measures ANOVA" was used for day-to-day intragroup comparisons that showed significantly improved learning by Day 4 as compared to Day 1 in all groups. All of the rats showed progressively enhanced learning over the 4-day test period.

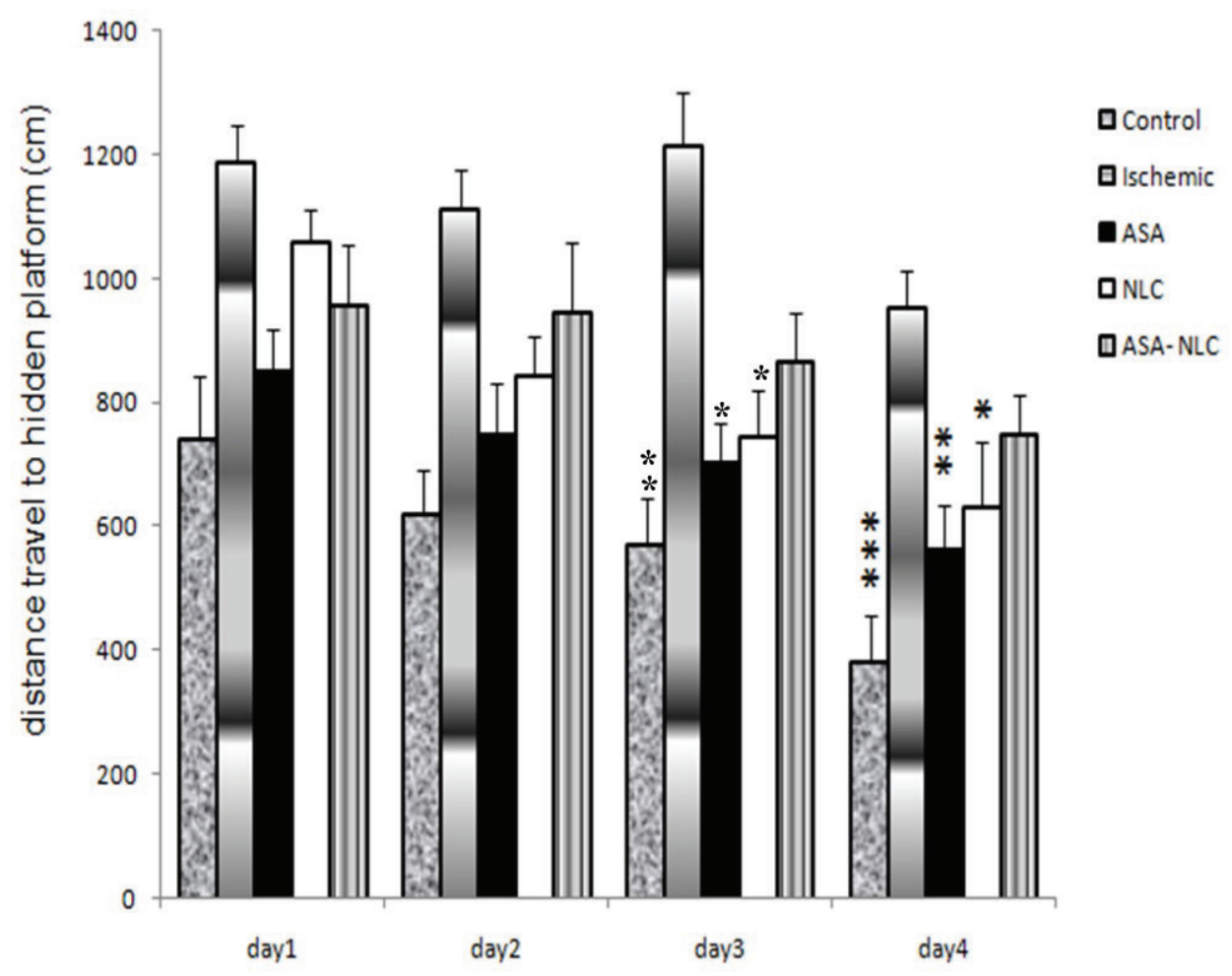

Figure 1: Spatial learning performance in the different groups: The distance traveled to locate the hidden platform. “*”indicates a significant difference when compared with the ischemic group. Day-to-day comparison between groups were analyzed using the "Repeated measures ANOVA". Distance traveled in the ischemic group was significantly higher than the control group. This parameter was significantly reduced in ASA and NLC groups in comparison to the ischemic group. Co- administration of aspirin and neural-like cells did not significantly improve the results compared with the ischemic group. ${ }^{*}, p \leq 0.05 ;{ }^{* *}, p \leq 0.01 ;{ }^{* \star *}, p \leq 0.001$

\section{Histopathological finding}

\section{Brain infarct volume}

TTC staining was employed to determine the infarct volume of the brain. It was absent in the control group, confirmed by a deep red color, but present in the other groups. The infarct volume was $1336 \pm 53.9,479.61 \pm 99.44$,
$564 \pm 35.33$ and $790 \pm 41.33 \mathrm{~mm}^{3}$ in Ischemic, ASA, NLC and ASA-NLC groups, respectively (Fig 5 and 6). Implantation of neural like cells after ischemia significantly reduced the infarct volume $(p=0.018)$ when compared with the ischemic group. Infarct volume in the ASA- NLC group was smaller than the ischemic group but did not reach significance ( $p=0.139)$. 


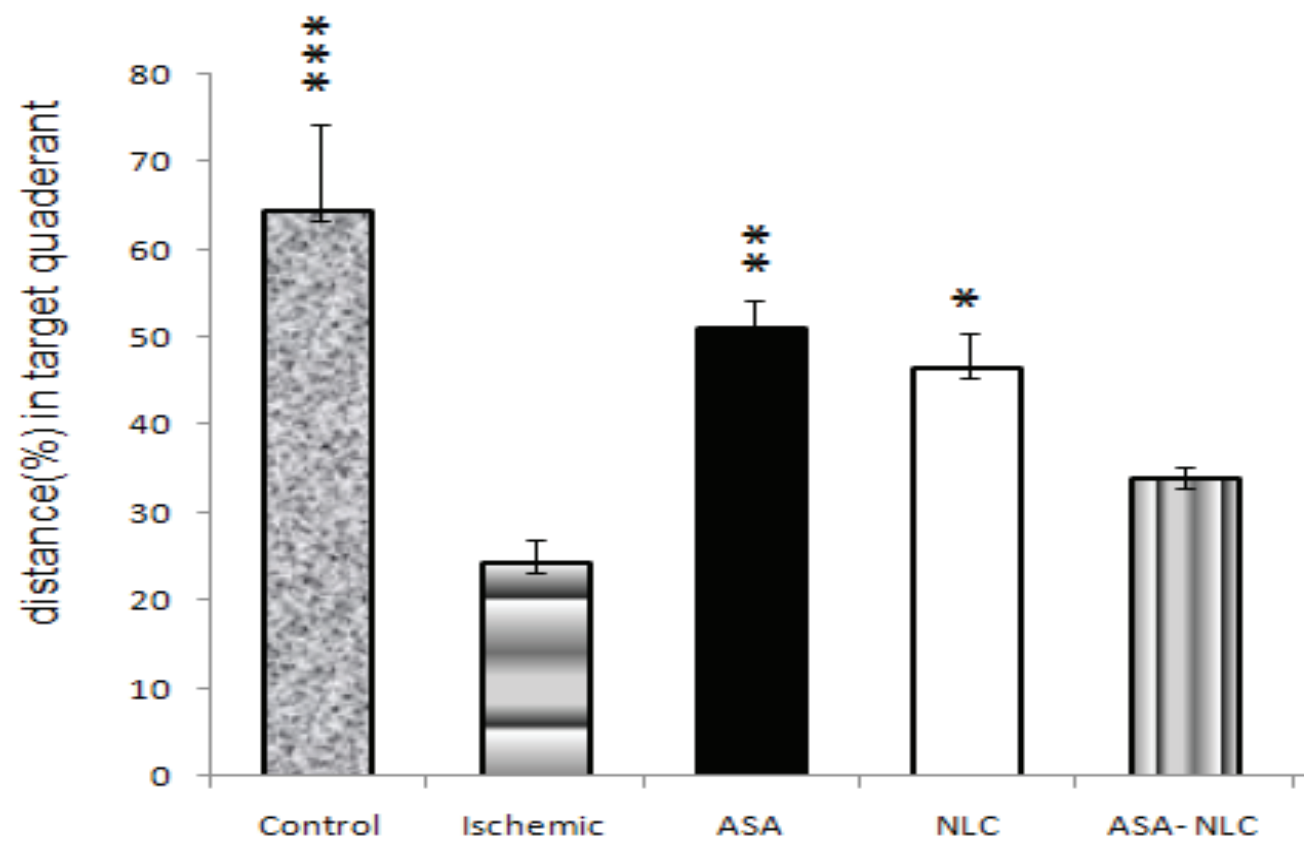

Figure 2: In the ischemic group, the percentage distance spent at target quadrant, was significantly less than that of the control group. Animals in ASA and NLC groups spent significantly more time in target quadrant compared with the ischemic group. Data are expressed as mean \pm SEM. * ${ }^{*} \leq \leq 0.05 ;{ }^{* *}, p \leq 0.01 ;{ }^{* *}, p \leq 0.001$.

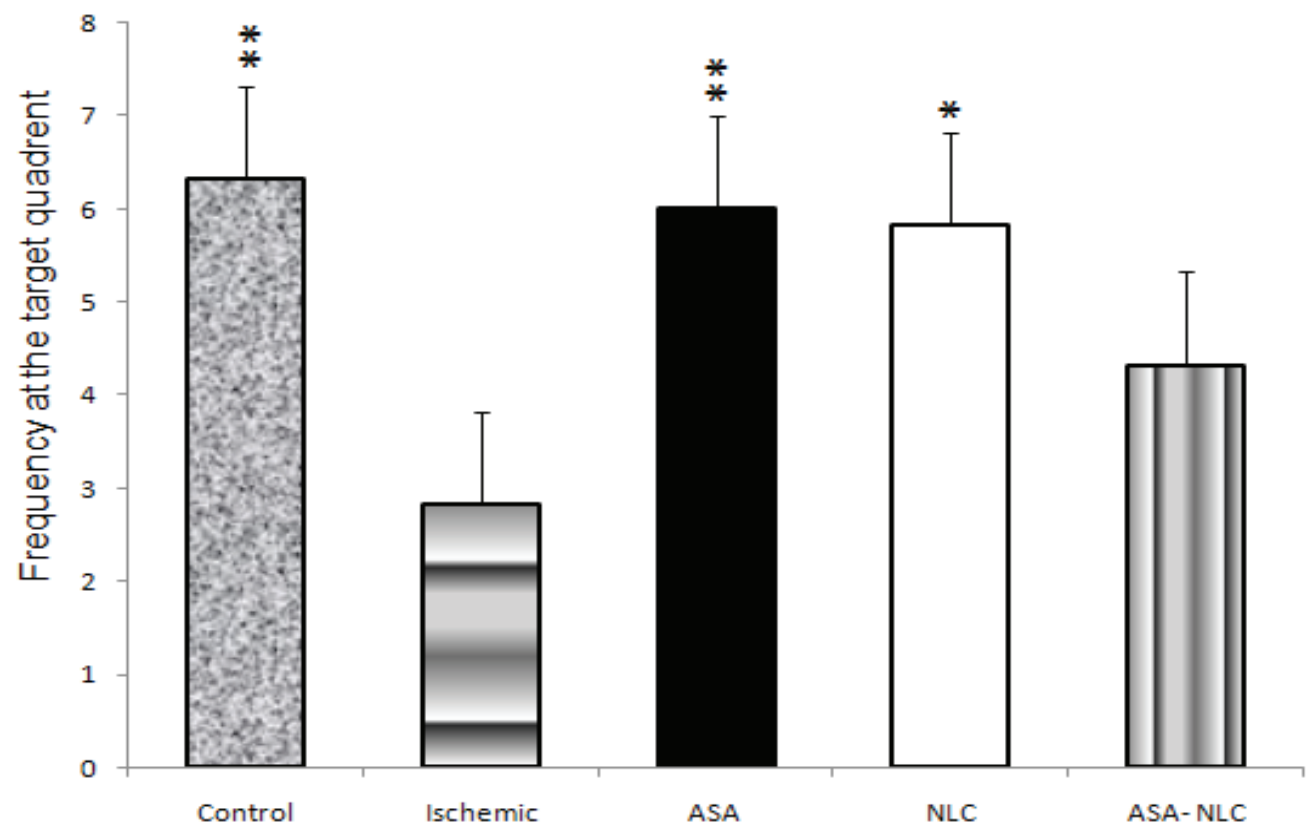

Figure 3: Ischemic animals significantly reduced the frequency of entrance to the target quadrant compared with the control animals. It was higher in the ASA and NLC groups compared with the ischemic animals. The frequency of entrance at target zone also decreased in ASA- NLC group. ${ }^{*}, \mathrm{p} \leq 0.05 ;{ }^{* \star}, \mathrm{p} \leq 0.01$. 

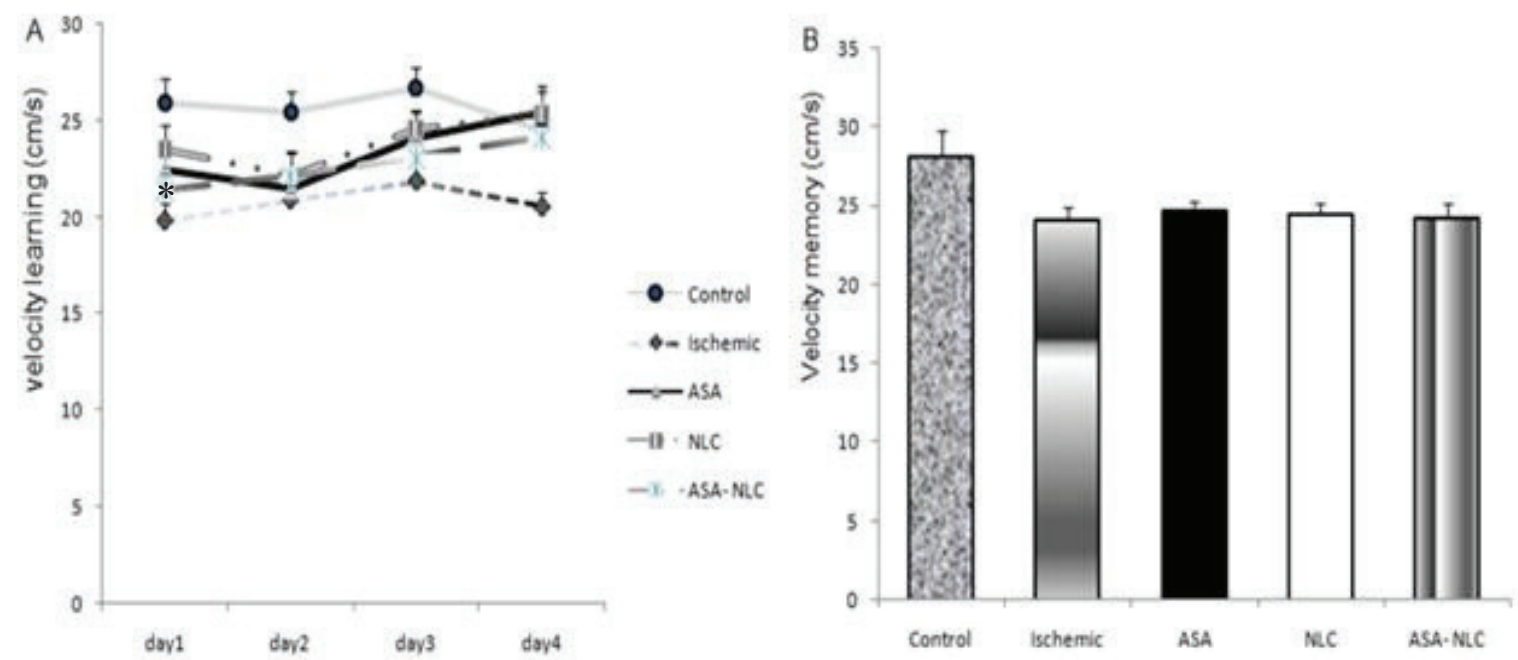

Figure 4: (A, B) Effects of aspirin and neural- like cell administration on swim speed (velocity) in learning and memory phase. Velocity learning and memory in either of the groups remained significantly unchanged in consecutive days except for the ischemic group on the 1st day in learning phase. Data were expressed as mean \pm S.E.M.
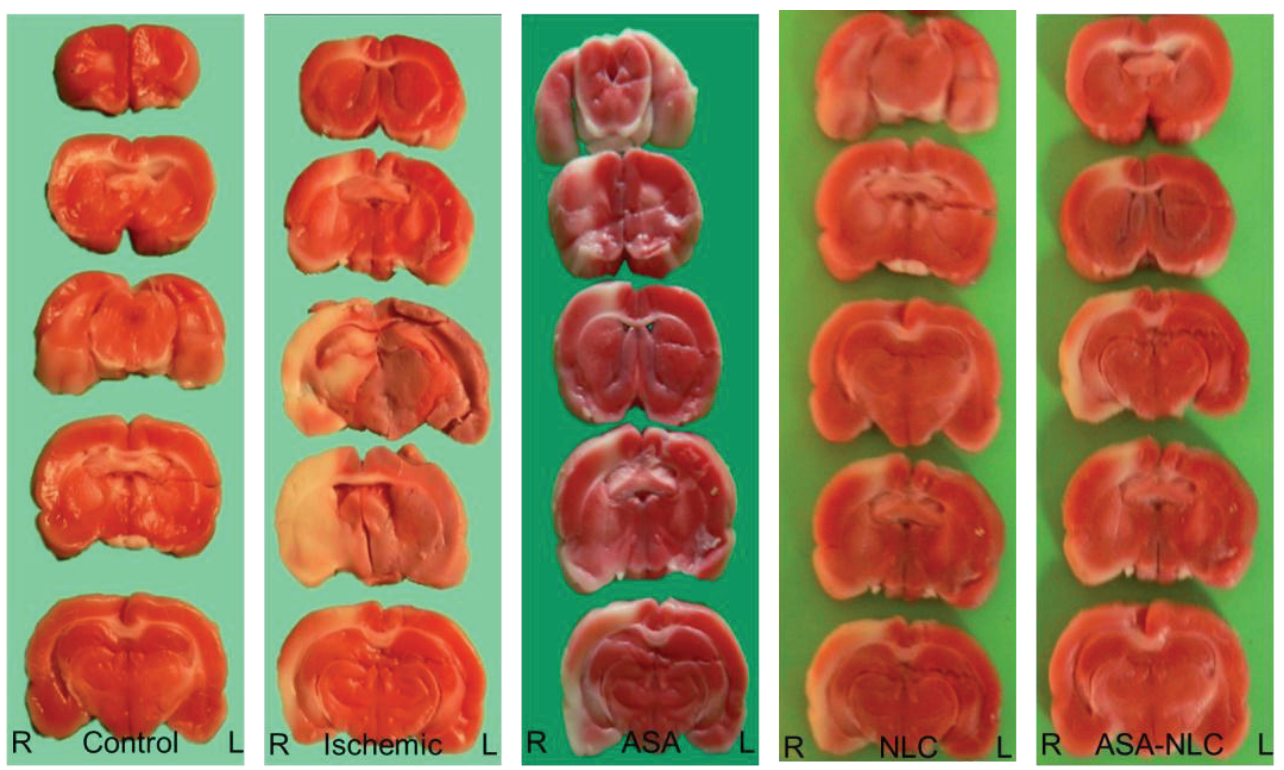

Figure 5: TTC staining displayed ischemic area (pale area) in all groups except the control group. Administration of ASA and neural-like cells resulted in a decrease of corrected infarct volume compared with the ischemic group.

\section{Hematoxyline \& Eosin findings}

Slices of hippocampus area were evaluated after H\&E staining. No degenerating pyramidal neurons in the CA1 area of the control group were detected. In contrast, pancellular necrosis with foamy cytoplasm, shrunken neurons and neuronal degeneration were observed in the ischemic group (Fig. 7). In the other groups, neuronal cell injury was also observed in the brain sections. The changes in ASA and NLC groups were less obvious than in the ischemic and ASA- NLC groups and few degenerated neural cells were observed in the same sections. The mean cell counts and the ratio of pancellular necrosis from CA1 hippocampus in all the groups indicated that the average number of degenerated cells had increased in the ischemic group compared with the other groups (Table 2 and Fig. 8). Aspirin and NLCs significantly decreased the proportion of degenerated cells compared 


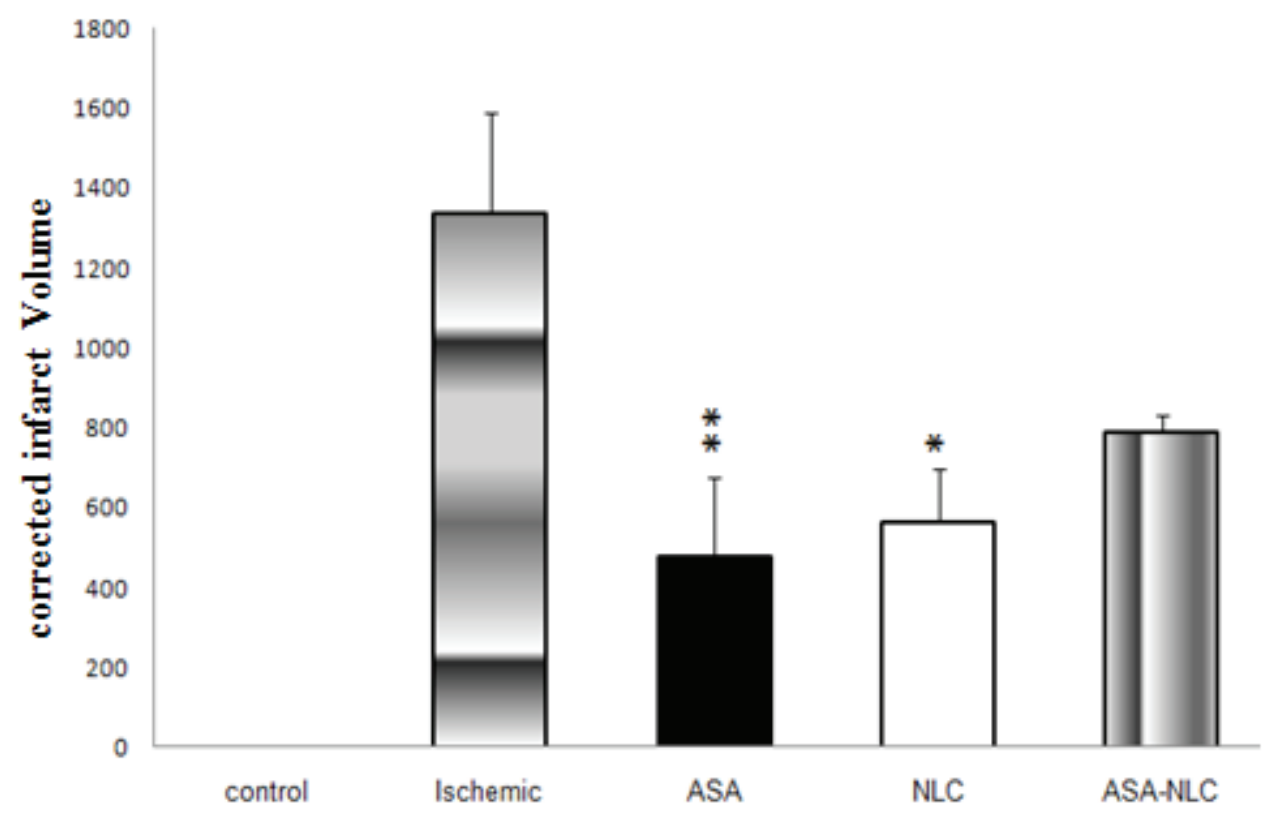

Figure 6: Corrected infarct volume decreased in all treatment groups compared with the Ischemic group. A statistically significant decrease was detected in ASA and NLC groups compared with the Ischemic group. * $p \leq 0.05 ;{ }^{* *}, p \leq 0.01$.

Table 2: Mean of all neurons (All), degenerative neural cells (Dc) and pancellular necrosis (Dc/All) in four fields from each section of the CA1 hippocampus.

\begin{tabular}{lllll}
\hline & Mean of all cells (All) & Mean of degenerated cells (DC) & $\begin{array}{l}\text { Ration of Pan cellular } \\
\text { Necrosis(DC/All) }\end{array}$ & $\begin{array}{l}\text { \% Pan cellular Necrosis } \\
(\text { DC/All) } \times 100\end{array}$ \\
\hline Control & $320 \pm 0.25$ & $25.25 \pm 0.25$ & $0.07 \pm 0.10$ & $7.86 \pm 0.57$ \\
Ischemic & $317 \pm 3.24$ & $266.3 \pm 1.2$ & $0.84 \pm 0.12$ & $84 \pm 1.66$ \\
ASA & $318.3 \pm 3.01$ & $77 \pm 0.57$ & $0.24 \pm 0.21$ & $24.19 \pm 0.75$ \\
NLC & $311.5 \pm 0.47$ & $93 \pm 0.65$ & $0.29 \pm 0.13$ & $29.85 \pm 1.11$ \\
ASA-NLC & $320.8 \pm 0.92$ & $140.3 \pm 0.48$ & $0.43 \pm 0.12$ & $43.73 \pm 1.40$ \\
\hline
\end{tabular}

The numbers indicated to mean of the all cells, degenerated, pancellular and the percent of pan cellular necrosis in each group.

with the Ischemic group $(77 \pm 0.57$ and $93 \pm 0.65$ cells vs $266.3 \pm 1.2$ cells, respectively). The number of degenerated cells in the ASA- NLC groups (140.3 \pm 0.48 cells) were higher than ASA and NLC groups.

\section{Mesenchymal cell markers expression and differentiation}

The majority of the cultured cells showed spindle and spherical appearance with short and long processes (Fig. 9A, B). Flow analysis of the hUCM cells revealed that mesenchymal markers CD73 and CD90 were highly expressed in these cells, while CD34 and CD45 were not considerably expressed (Fig. 9D). Additionally, the red color of the cells represented the extracellular matrix after alizarin red staining, indicating the production of calcium phosphate crystals by the osteogenic induced cells (Fig. 9C). According to oil red staining results, hUCMs cells differentiated well into adipogenic cells. Lipid droplets appeared from the fourth and fifth day of the onset of adipogenic differentiation, grew gradually towards the end of the induction period and the red droplets were observed after staining (Fig. 9C).

\section{In vitro neuronal differentiation of hUCMs}

hUCMs were cultured in neuronal differentiation media for 6 days $\left(6^{+}, 6\right)$. Many cells displayed neural-like outgrowth 

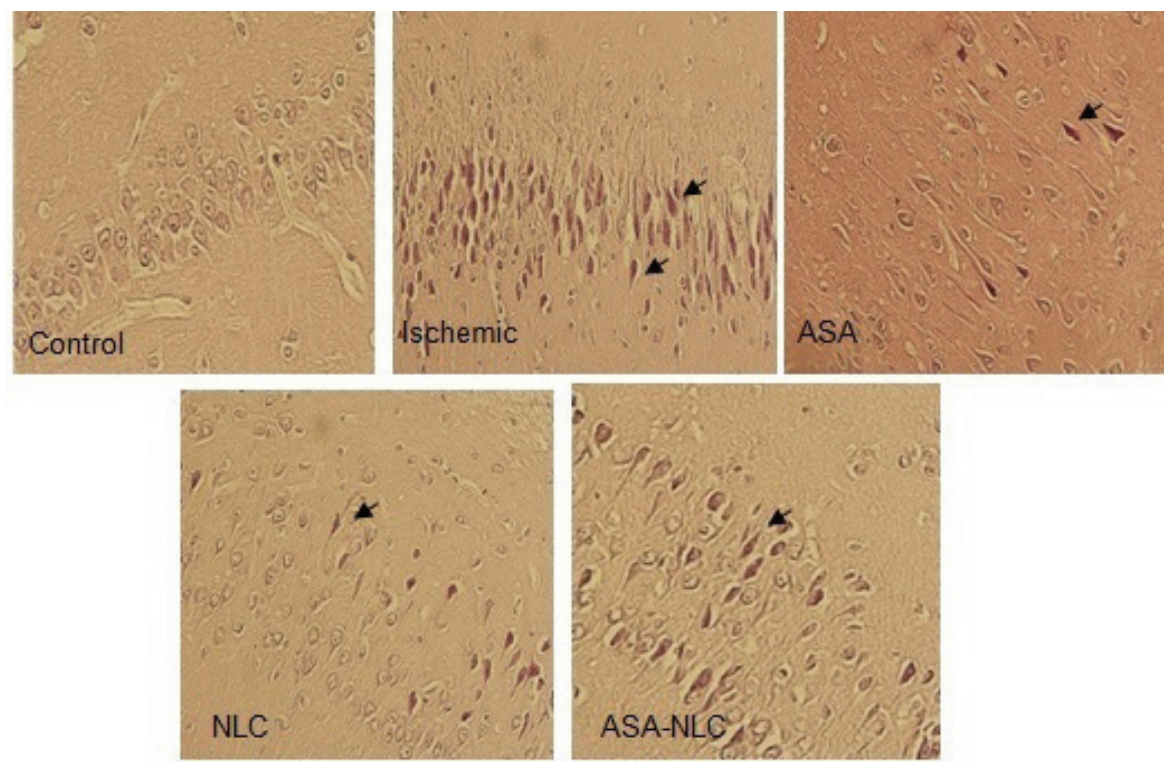

Figure 7: Slices of brain tissue stained by H\&E. In the ischemic group, necrosis, foamy cytoplasm, shrunken neurons, and neuronal degeneration was observed. Magnification, $\times 200$.

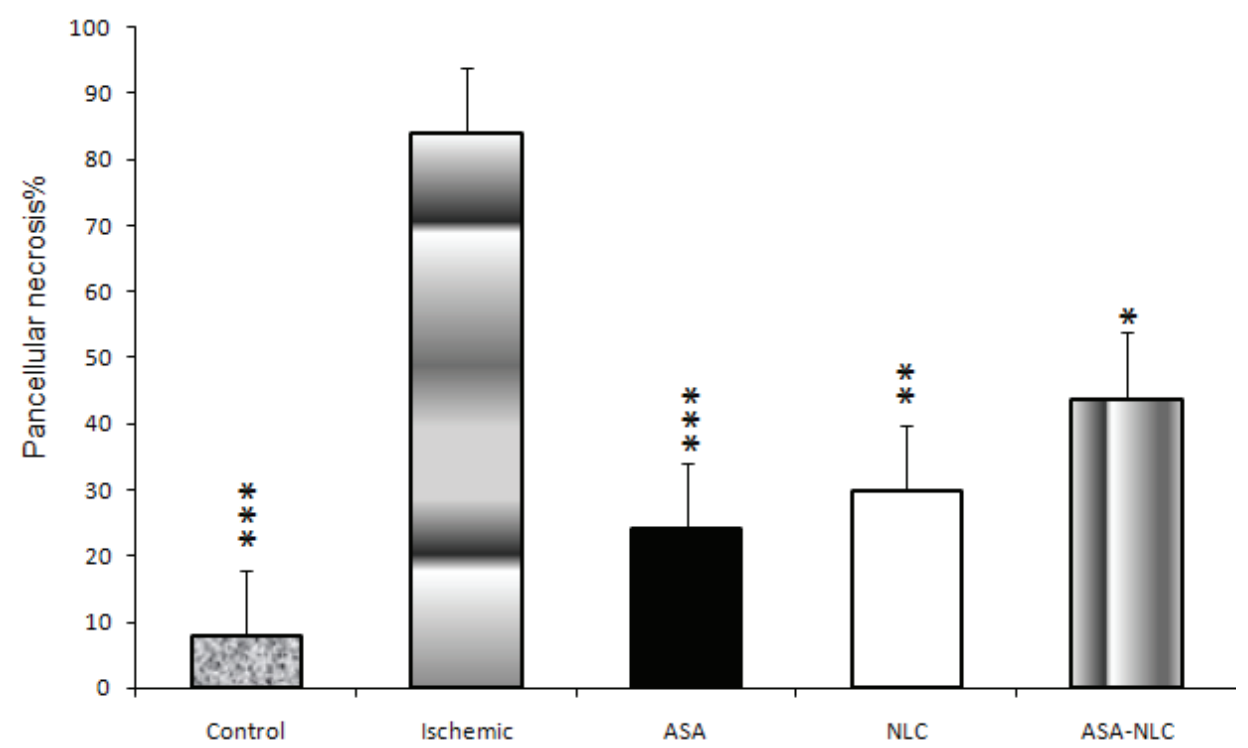

Figure 8: Pancellular Necrosis from the CA1 hippocampus in the different groups. A statistically significant decrease was detected in the proportion of pancellular necrosis in all treatment groups compared with the ischemic group. ${ }^{\star}, p \leq 0.05,{ }^{\star \star}, p \leq 0.01 ;{ }^{\star \star \star}, p \leq 0.001$.

12 days after the induction. The induced cells stained well for neuron-specific markers like nestin, neurofilament (NF) and GFAP (Fig. 10 A). Nestin is mainly located around nuclei of differentiated hUCMs. The induced and control cells were positively and negatively stained for nestin at day 12, respectively. Neurofilament marker (NF) was positively expressed in the induced cells. These data suggest that 6 days incubation of hUCMs in the presence of RA was sufficient for differentiation into NLCs. In addition, induced hUCMs were reactive for the astrocyte marker; GFAP, which highly expressed in the NLC group but not in the control group.

\section{Neuronal gene expression in the NLCs}

Expression of neural markers were determined by RT-PCR. NLCs expressed significantly higher levels of Nestin and ß-tubulin III in contrast to the hUCMs (Fig. $10 \mathrm{~B}$ ). 

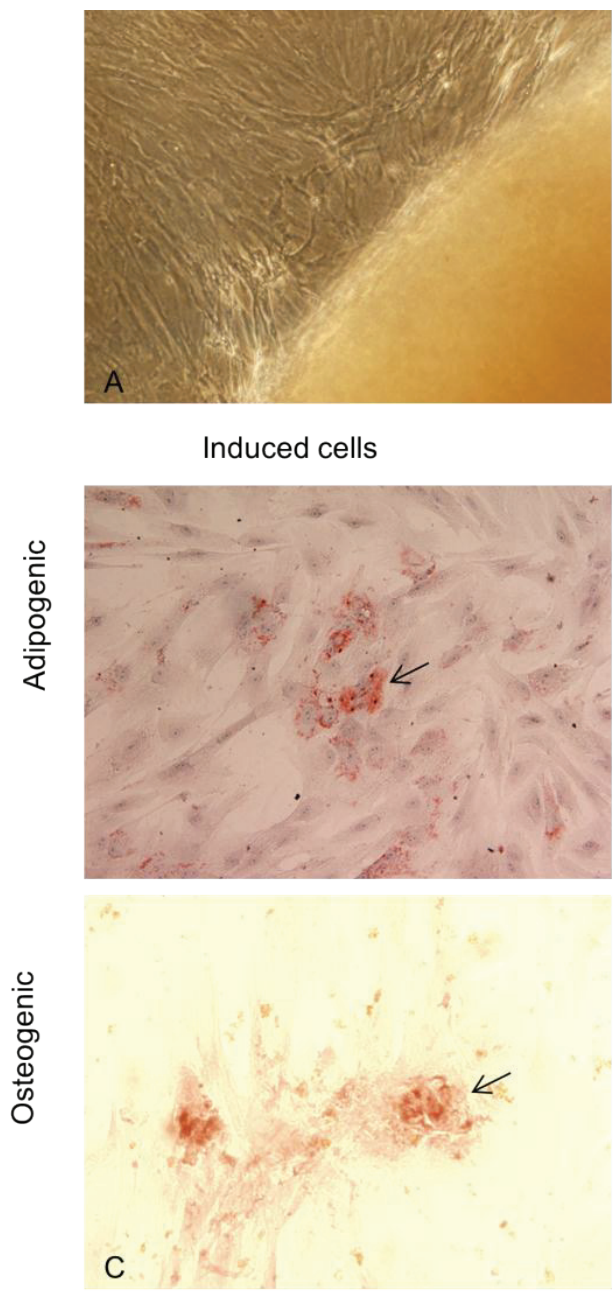

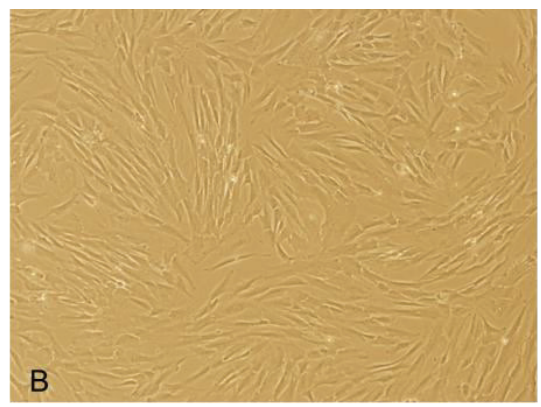

Negative control
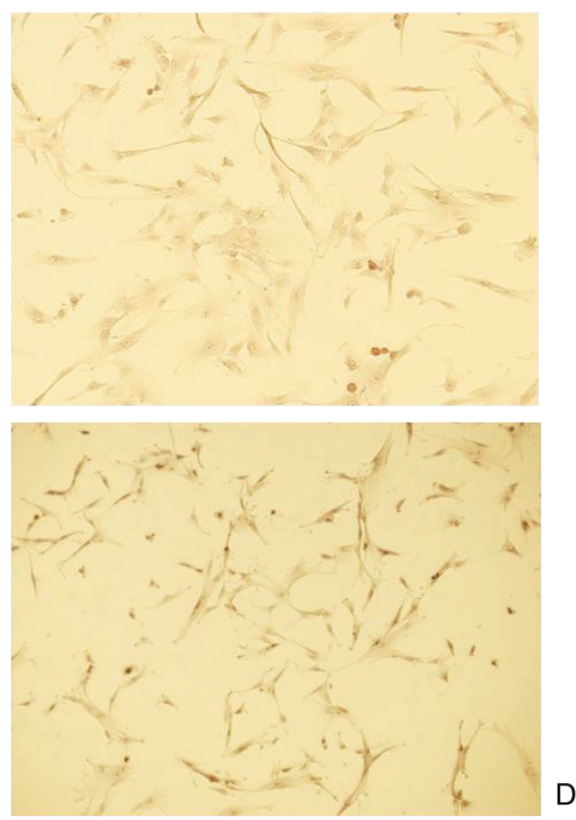
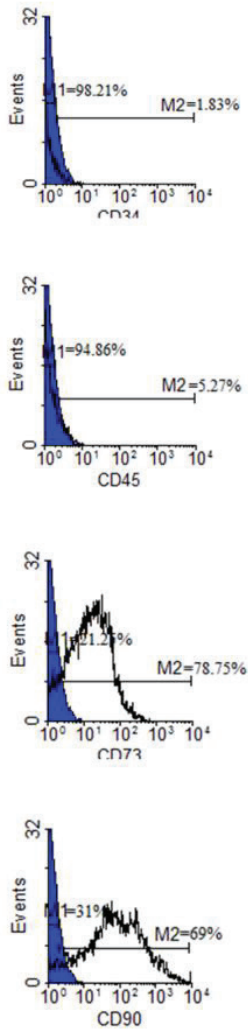

Figure 9: (A, B) hUCMs cells appeared with a fibroblast like morphology when in culture, showing short and long processes. (C) Osteogenic and adipogenic differentiation of hUCMs. Their adipocytic phenotypes were signaled by the appearance of tiny intracytoplasmic lipid droplets with Oil red. Calcium deposition and osteoid formation as shown by Alizarin red. Negative control showed no evidence of staining. (D) Flow cytometry results. The blue histograms are the isotype control-stained cells; the white histograms are the antibody-stained cells. hUCM cells were negative for hematopoietic markers; CD34 and CD45. These cells were positive for mesenchymal cell markers; CD73 and CD90.

\section{Cells migration}

On the $10^{\text {th }}$ day of intravenous injection of $\mathrm{PKH}^{26+}$ cells, brain slices were obtained and $\mathrm{PKH}^{26+}$ cells were assessed within the brain tissue (Fig. 11). On the sixteenth day after ischemic induction, we found few labeled cells in the brain sections.

\section{Discussion}

This study was designed to determine the effect of coadministration of neural like cells (NLC) and acetylsalicylic acid on brain stroke induced by transient middle cerebral artery occlusion. Our findings indicated that
MCA occlusion induced severe neural impairment, brain damage and learning and spatial memory defects in male rats.

From a behavioral perspective, stroked animals that underwent treatment by aspirin or NLCs improved their performance in MWM task compared with the ischemic animals. They also had a good memory as demonstrated in the probe test (the $5^{\text {th }}$ day). Learning and cognitive memory experiments on the ASA treated animals compared with the NLC treated ones showed no significant difference, considering distance travel or frequency in target quadrant during MWM training. On the other hand, treatment of stroked animals with ASA or NLCs displayed relatively higher improvement in cognitive memory compared with the co-administration of ASA with NLC. 
A
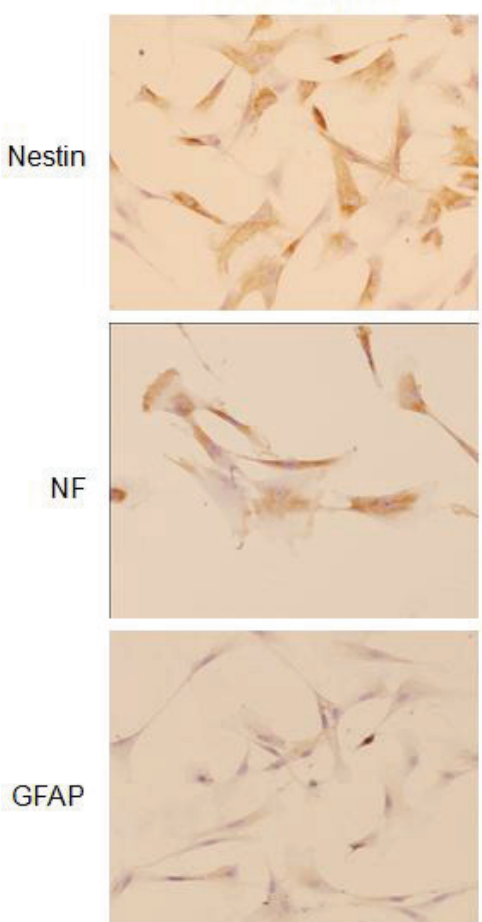

Negative
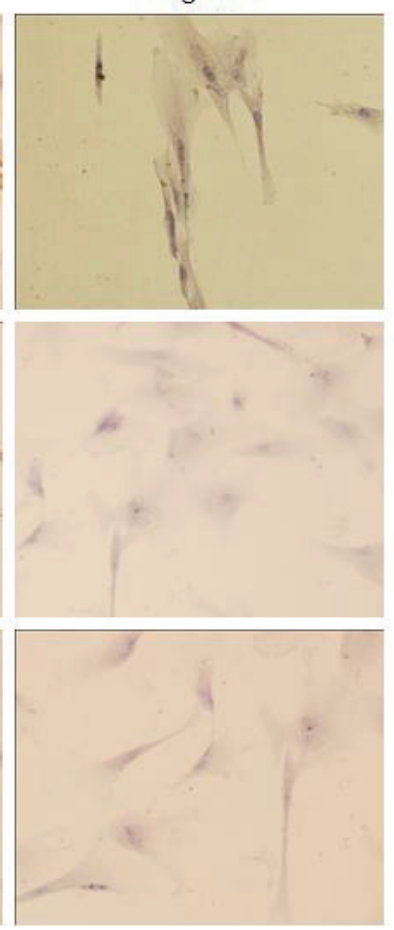

B

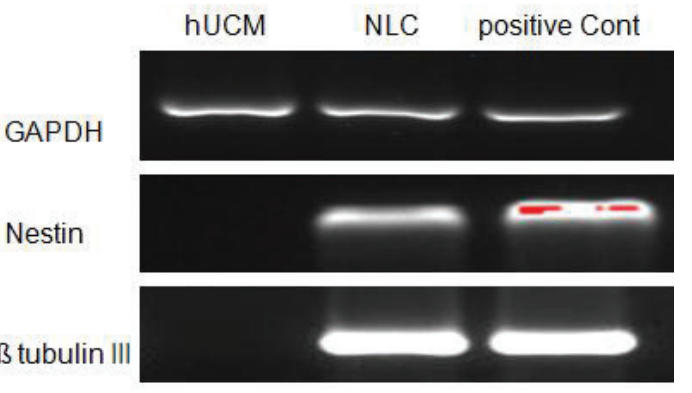

Figure 10: (A) Images represent an expression of specific neural and glial markers by immunocytochemistry. Expression of nestin, NF and GFAP in differentiated hUCMs. Also, immunocytochemical staining of hUCMs were shown as a negative control. (In all images, original magnification $\times 400)(B)$ RT- PCR show expression of nestin and B-tubulin III in differentiated hUCMs. In addition, RT- PCR of hUCMs was applied as negative control.

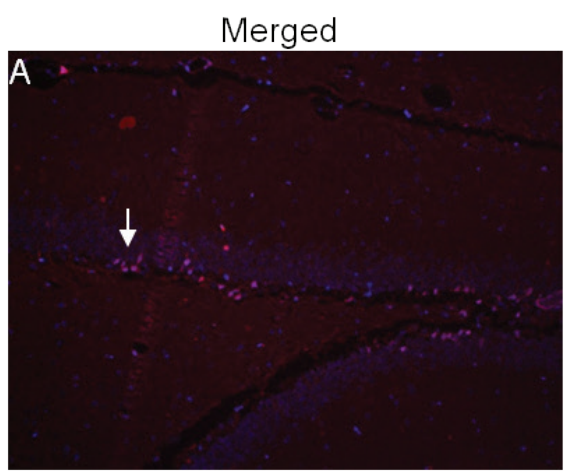

$\mathrm{PKH} 26$

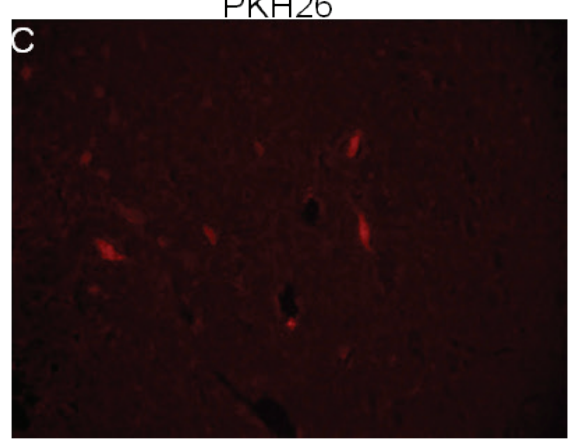

Hokhst

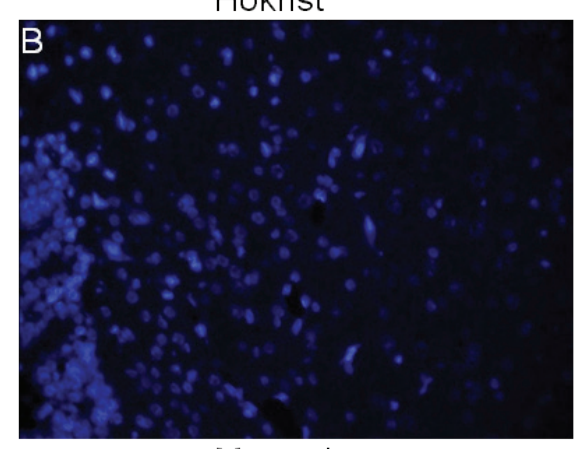

Merged

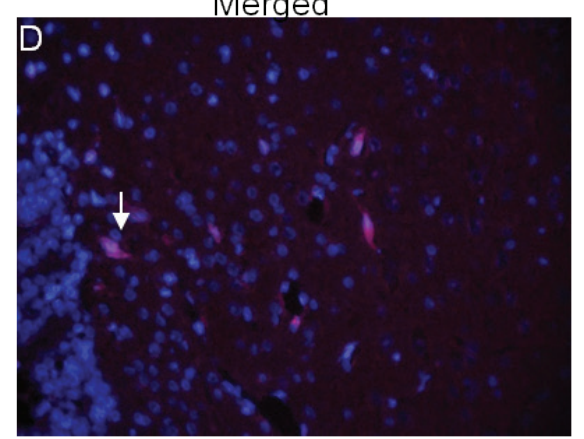

Figure 11: $\mathrm{PKH}^{26}$ was used to determine stem cell migration into the brain. The sections were obtained 150 days after intravenous injection (Original magnification A: $\times 20 . \mathrm{B}, \mathrm{C}, \mathrm{D}: \times 40$ ). 
It is generally accepted that learning and memory deficits are common to all cerebral ischemia, so the assay of these defects is an essential part of the overall understanding. For this reason, we determined three main parameters of Morris water maze to valuate spatial learning and memory deficits. Studies conducted thus far have reported the neuroprotective effects of some drugs on cognitive performance $(41,23)$. However, the effect of acetylsalicylic acid and stem cells in memory impairments has not been investigated in the animal models of brain ischemia, with special attention to aspirin administration in combination with mesenchymal cells. Our results on the effect of aspirin in learning and cognitive memory following brain ischemia are comparable with those reported by Jeremy Smith (41) and Kara (23). Aspirin administration has been reported to improve cognitive state and antioxidative status in serum (23) but the mechanism of action is still unclear.

Cytokines and trophic factors produced by mesenchymal cells may limit the extent of ischemic area and improve the recovery of the brain function after stroke $(8,46)$. De Paula et al., reported that functional recovery was not significantly altered following implantation of human umbilical cord blood cells in the brain of ischemic animals (9). Our results showed that administration of NLC $24 \mathrm{~h}$ after the induction of stroke improved cognitive condition significantly. Intravenous application of NLCs and migration of these cells towards the injured tissue might have provided trophic factors responsible in the recovery of the ischemic animals.

Cerebral ischemia leads to disadvantageous changes in $\operatorname{NMDA}(3,33)$ and AMPA receptors (11) and the reason for the negative effects of ischemia on learning and memory. Ma et al., showed that the transplanted cells significantly improved the learning and memory deficits 3-weeks post transplantation, by injecting mice embryonic stem cells directly into the lesion site (30). Both intracerebral and i.v. injection of stem cells resulted in behavioral improvement in ischemic rats, although the percentage of graft survival was small (9). Borlongan et al., (6) showed that in contrast with intracerebral transplantation, i.v. delivery of bone marrow stem cells produced only limited functional recoveries in the stroked rats. This may be true in our study, where low functional recovery in distance memory of NLC treated animals could be related to the small number of $\mathrm{PKH}^{26}$ positive cells in the brain tissue.

Since the swim speeds were not significantly different between groups on the fourth day, we believe that the improvement in learning was not due to the increasing motoric activity or limb flexibility especially since most of the motor cortex lies in the area supplied by the MCA (11).
NLCs were present in the ischemic area $24-72 \mathrm{~h}$ after the induction of ischemia. High expression of chemokines from the injured brain has been reported recently (13). Cerebral ischemia occurs following reduction of blood flow in the middle cerebral artery, which is the main feeding artery of the brain (1). Complex disorders occur in related areas including oxidative stress, damage to small blood vessels, blood brain barrier dysfunction and inflammation which mediate neural, glial and endothelial cell death $(31,19,28)$.

TTC and H\&E staining confirmed histopathological changes and the neuroprotective effects of aspirin and NLCs in the different groups. Cortical infarct area was observed in ischemic as well as other treatment groups compared with the control group. Animals in the ASA and NLC groups had significantly less infarct volume than the ischemic group. Co-administration of aspirin and NLCs (ASA- NLC group) increased the ischemic region and infarct volume compared with the other treatment groups. The pale infarct area and the penumbra transition zone (zone between the pale-ischemic core and redcolored healthy tissue) represent the best response to the treatment $(21,31,27)$. The pale area is generated following reduction in blood supply which alters microcirculation of the brain and causes a decrease in glucose and oxygen, accumulation of lactate, acidosis and increasing free radical formation, intermediation with intracellular protein synthesis and cell swelling, more lipases and proteases function and finally cell death $(1,20)$. Results from light microscopy showed the apoptotic and necrotic changes of CA1 hippocampal neurons following transient MCAO including formation of apoptotic bodies and loss of inflammatory cells. Our histological data indicates that ASA and NLCs could protect the normal histology of CA1 pyramidal cells after transient ischemia. This event was significantly observed in the ASA-NLC group as well.

Morphologic analysis showed that brain ischemia resulted in extensively degenerated cells and i.v. injection of NLC were able to significantly reduce the mean number of affected cells, so NLCs could have histopathologically protected the brain tissue against transient global ischemia.

In vitro exposure of mesenchymal cells to ASA have been reported to decrease MSCs activity. ASA could inhibit Wnt / ß-catenin signaling and activate the mitochondrial apoptotic pathway (10). ASA also suppresses cyclooxygenase (COX) enzyme activity (44). An increase in the ischemic area following ASA- NLC treatment in TMCAO animals may be related to the inhibition of COX enzyme activity or the Wnt/ß-catenin pathway impairment which requires further experiments. 
NLCs were transplanted through tail vein in stroked animals. Numbers of transplanted cells have been reported to infiltrate in the liver and lungs and small number of cells have been detected in the brain $(8,7,45,9)$. We sacrificed the animals after 15 days of treatment and assessed the brain tissue for labeled-NLCs. Whether altering parameters e.g. higher number of injected cells, delayed sacrifice of the treated animals or different injection methods such as intracerebral and intra-arterial route, could improve the outcome requires further consideration.

In this study, we used RA in combination with growth factors for differentiation of hUCMs towards NLCs. After six days of treatment with RA, we could successfully observe neural cell morphology in the culture. It was confirmed by the expression of neural markers by ICC and RT-PCR. Differentiated hUCMs expressed Nestin, ß-tubulin III, $\mathrm{NF}$ and GFAP. These markers have been expressed in the differentiated MSCs $(22,43)$ but not in undifferentiated cells.

In conclusion, aspirin and NLC could efficiently alter brain ischemic progress in male rats, by improving learning and memory conditions and by reduction of the infarcted area. Co- administration of ASA and NLC can also reduce the ischemic injury deficits but the outcome is poorer than with ASA or NLC alone. The underlying mechanisms involved in the reduced improvement following co-administration of ASA and NLC needs further investigation We therefore suggest if the stroked patients are to be given the chance of NLC treatment, simultaneous ASA should be administered with precaution.

\section{References}

1. Adams H. P., Hachinski V. and Norris J. W. (2001). Ischemic cerebrovascular disease, Oxford University Press New York, NY;.

2. Aghaee-Afshar M., Rezazadehkermani M., Asadi A., MalekpourAfshar R., Shahesmaeili A. and Nematollahi-mahani S. N. Potential of human umbilical cord matrix and rabbit bone marrow-derived mesenchymal stem cells in repair of surgically incised rabbit external anal sphincter. Diseases of the Colon \& Rectum 2009; 52: 1753-1761

3. Arundine M. and Tymianski M. Molecular mechanisms of glutamate-dependent neurodegeneration in ischemia and traumatic brain injury. Cellular and Molecular Life Sciences CMLS 2004; 61: 657-668

4. Asadi-Shekaari M., Eftekhar Vaghefi H., Sheibani V., Shams Ara A. and Behbahani P. Antiapoptotic Effects of Aspirin on CA1 Pyramidal Neurons in Adult Rats. Iranian Journal of Pathology 2011; 6: 187-192
5. Berger C., Xia F., Schabitz W.-R., Schwab S. and Grau A. Highdose aspirin is neuroprotective in a rat focal ischemia model. Brain research 2004; 998: 237-242

6. Borlongan C. V., Evans A., Yu G. and Hess D. C. Limitations of intravenous human bone marrow CD133+ cell grafts in stroke rats. Brain research 2005; 1048: 116-122

7. Borlongan C. V., Hadman M., Sanberg C. D. and Sanberg P. R. Central nervous system entry of peripherally injected umbilical cord blood cells is not required for neuroprotection in stroke. Stroke 2004; 35: 2385-2389

8. Chen J., Sanberg P. R., Li Y., Wang L., Lu M., Willing A. E., Sanchez-Ramos J. and Chopp M. Intravenous administration of human umbilical cord blood reduces behavioral deficits after stroke in rats. Stroke 2001; 32: 2682-2688

9. de Paula S., Vitola A. S., Greggio S., de Paula D., Mello P. B., Lubianca J. M., Xavier L. L., Fiori H. H. and Dacosta J. C. Hemispheric brain injury and behavioral deficits induced by severe neonatal hypoxia-ischemia in rats are not attenuated by intravenous administration of human umbilical cord blood cells. Pediatric research 2009; 65: 631-635

10. Deng L., Hu S., Baydoun A., Chen J., Chen X. and Cong X. Aspirin induces apoptosis in mesenchymal stem cells requiring Wnt/ $\beta$-catenin pathway. Cell proliferation 2009; 42: 721-730

11. Dirnagl U., ladecola C. and Moskowitz M. A. Pathobiology of ischaemic stroke: an integrated view. Trends in neurosciences 1999; 22: 391-397

12. Donega V., van Velthoven C. T., Nijboer C. H., van Bel F., Kas M. J., Kavelaars A. and Heijnen C. J. Intranasal mesenchymal stem cell treatment for neonatal brain damage: long-term cognitive and sensorimotor improvement. PloS one 2013; 8: e51253

13. Drago D., Cossetti C., Iraci N., Gaude E., Musco G., Bachi A. and Pluchino $S$. The stem cell secretome and its role in brain repair. Biochimie 2013; 95: 2271-2285

14. Durukan A. and Tatlisumak T. Acute ischemic stroke: overview of major experimental rodent models, pathophysiology, and therapy of focal cerebral ischemia. Pharmacology Biochemistry and Behavior 2007; 87: 179-197

15. Eftekhar-Vaghefi S. H., Zahmatkesh L., Salehinejad P., Totonchi S. and Shams-Ara A. Evaluation of Neurogenic Potential of Human Umbilical Cord Mesenchymal Cells; a Time-and Concentration-Dependent Manner. Iranian Biomedical Journal 2015; 19: 82-90

16. Fu Y.-S., Shih Y.-T., Cheng Y.-C. and Min M.-Y. Transformation of human umbilical mesenchymal cells into neurons in vitro. Journal of biomedical science 2004; 11: 652-660

17. Gregory C. A., Prockop D. J. and Spees J. L. Non-hematopoietic bone marrow stem cells: molecular control of expansion and differentiation. Experimental cell research 2005; 306: 330-335

18. Gu N., Rao C., Tian Y., Di Z., Liu Z., Chang M. and Lei H. Antiinflammatory and antiapoptotic effects of mesenchymal stem cells transplantation in rat brain with cerebral ischemia. Journal of Stroke and Cerebrovascular Diseases 2014; 23: 2598-2606

19. Hoffman G. E., Merchenthaler I. and Zup S. L. Neuroprotection by ovarian hormones in animal models of neurological disease. Endocrine 2006; 29: 217-231

20. Huang Y. and McNamara J. O. Ischemic stroke:"acidotoxicity" is a perpetrator. Cell 2004; 118: 665-666

21. Isayama K., Pitts L. H. and Nishimura M. C. Evaluation of 2, 3, 5-triphenyltetrazolium chloride staining to delineate rat brain infarcts. Stroke 1991; 22: 1394-1398 
22. Jurga M., Markiewicz I., Sarnowska A., Habich A., Kozlowska H., Lukomska B., Buzanska L. and Domanska-Janik K. Neurogenic potential of human umbilical cord blood: Neural-like stem cells depend on previous long-term culture conditions. Journal of neuroscience research 2006; 83: 627-637

23. Kara Y., Doguc D. K., Kulac E. and Gultekin F. Acetylsalicylic acid and ascorbic acid combination improves cognition; Via antioxidant effect or increased expression of NMDARs and nAChRs? Environmental toxicology and pharmacology 2014; 37: 916-927

24. Karamouzian S., Nematollahi-Mahani S. N., Nakhaee N. and Eskandary $\mathrm{H}$. Clinical safety and primary efficacy of bone marrow mesenchymal cell transplantation in subacute spinal cord injured patients. Clinical neurology and neurosurgery 2012; 114: 935-939

25. Khaja A. M. and Grotta J. R. Established treatments for acute ischaemic stroke. lancet 2007; 369: 319-330

26. Koh S.-H., Kim K. S., Choi M. R., Jung K. H., Park K. S., Chai Y. G., Roh W., Hwang S. J., Ko H.-J. and Huh Y.-M. Implantation of human umbilical cord-derived mesenchymal stem cells as a neuroprotective therapy for ischemic stroke in rats. Brain research 2008; 1229: 233-248

27. Kramer M., Dang J., Baertling F., Denecke B., Clarner T., Kirsch C., Beyer C. and Kipp M. TTC staining of damaged brain areas after MCA occlusion in the rat does not constrict quantitative gene and protein analyses. Journal of neuroscience methods 2010; 187: 84-89

28. Lorenz L., Dang J., Misiak M., Tameh Abolfazl A., Beyer C. and Kipp M. Combined 17 $\beta$-Oestradiol and Progesterone Treatment Prevents Neuronal Cell Injury in Cortical but not Midbrain Neurones or Neuroblastoma Cells. Journal of neuroendocrinology 2009; 21: 841-849

29. Lu J., Moochhala S., Moore X.-L., Ng K. C., Tan M. H., Lee L. K. H., He B., Wong M. C. and Ling E.-A. Adult bone marrow cells differentiate into neural phenotypes and improve functional recovery in rats following traumatic brain injury. Neuroscience letters 2006; 398: 12-17

30. Ma J., Wang Y., Yang J., Yang M., Chang K.-A., Zhang L., Jiang F., Li Y., Zhang Z. and Heo C. Treatment of hypoxic-ischemic encephalopathy in mouse by transplantation of embryonic stem cell-derived cells. Neurochemistry international 2007; 51: 57-65

31. Marcheselli V. L., Hong S., Lukiw W. J., Tian X. H., Gronert K., Musto A., Hardy M., Gimenez J. M., Chiang N. and Serhan C. N. Novel docosanoids inhibit brain ischemia-reperfusionmediated leukocyte infiltration and pro-inflammatory gene expression. Journal of Biological Chemistry 2003; 278: 4380743817

32. Massood E., Maryam K., Parvin S., Mojgan M. and Noureddin N.-M. S. Vitrification of human umbilical cord wharton's jelly-derived mesenchymal stem cells. CryoLetters 2013; 34: 471-480

33. Mehta S. L., Manhas N. and Raghubir R. Molecular targets in cerebral ischemia for developing novel therapeutics. Brain research reviews 2007; 54: 34-66

34. Miller R. H. The promise of stem cells for neural repair. Brain research 2006; 1091: 258-264
35. Rossato J. I., Bevilaqua L. R., Myskiw J. C., Medina J. H., Izquierdo I. and Cammarota M. On the role of hippocampal protein synthesis in the consolidation and reconsolidation of object recognition memory. Learning \& Memory 2007; 14: 36-46

36. Sacco R. L., Chong J. Y., Prabhakaran S. and Elkind M. S. Experimental treatments for acute ischaemic stroke. The Lancet 2007; 369: 331-341

37. Salehinejad P., Alitheen N. B., Ali A. M., Omar A. R., Mohit M., Janzamin E., Samani F. S., Torshizi Z. and Nematollahi-Mahani S. N. Comparison of different methods for the isolation of mesenchymal stem cells from human umbilical cord Wharton's jelly. In Vitro Cellular \& Developmental Biology-Animal 2012; 48: $75-83$

38. Salehinejad P., Alitheen N. B., Ali A. M., Omar A. R., Moshrefi M., Motamedi B. and Nematollahi-Mahani S. N. Neural differentiation of human umbilical cord matrix-derived mesenchymal cells under special culture conditions. Cytotechnology 2015; 67:449-460

39. Seyedi F., Farsinejad A., Moshrefi M. and Nematollahi-Mahani S. N. In vitro evaluation of different protocols for the induction of mesenchymal stem cells to insulin-producing cells. In Vitro Cellular \& Developmental Biology-Animal 2015; 51: 886-878

40. Shams ara A., Sheibani V., Esmaeilpour K., Eslaminejad T. and Nematollahi-Mahani S. N. Coadministration of the Human Umbilical Cord Matrix-Derived Mesenchymal Cells and Aspirin Alters Postischemic Brain Injury in Rats. Journal of Stroke and Cerebrovascular Diseases 2015; 24 (9): 2005-2016

41. Smith J. W., Al-Khamees O., Costall B., Naylor R. J. and Smythe J. W. Chronic aspirin ingestion improves spatial learning in adult and aged rats. Pharmacology Biochemistry and Behavior 2002; 71: 233-238

42. Tamura A., Graham D., McCulloch J. and Teasdale G. Focal cerebral ischaemia in the rat: 1 . Description of technique and early neuropathological consequences following middle cerebral artery occlusion. Journal of Cerebral Blood Flow \& Metabolism 1981; 1: 53-60

43. Tio M., Tan K. H., Lee W., Wang T. T. and Udolph G. Roles of db-CAMP, IBMX and RA in aspects of neural differentiation of cord blood derived mesenchymal-like stem cells. PLoS One 2010; 5: e9398

44. Vane J. and Botting R. The mechanism of action of aspirin. Thrombosis research 2003; 110: 255-258

45. Vendrame M., Cassady J., Newcomb J., Butler T., Pennypacker K. R., Zigova T., Sanberg C. D., Sanberg P. R. and Willing A. E. Infusion of human umbilical cord blood cells in a rat model of stroke dose-dependently rescues behavioral deficits and reduces infarct volume. Stroke 2004; 35: 2390-2395

46. Yoshimura S., Takagi Y., Harada J., Teramoto T., Thomas S. S., Waeber C., Bakowska J. C., Breakefield X. O. and Moskowitz M. A. FGF-2 regulation of neurogenesis in adult hippocampus after brain injury. Proceedings of the National Academy of Sciences 2001; 98: 5874-5879

47. Zheng Z., Schwab S., Grau A. and Berger C. Neuroprotection by early and delayed treatment of acute stroke with high dose aspirin. Brain research 2007; 1186: 275-280 